\title{
Identification and characterization of two novel classes of small RNAs in the mouse germline: retrotransposon-derived siRNAs in oocytes and germline small RNAs in testes
}

\author{
Toshiaki Watanabe, ${ }^{1,2,3,6}$ Atsushi Takeda, ${ }^{4,5}$ Tomoyuki Tsukiyama, ${ }^{1}$ Kazuyuki Mise, ${ }^{4}$ \\ Tetsuro Okuno, ${ }^{4}$ Hiroyuki Sasaki, ${ }^{2,3}$ Naojiro Minami, ${ }^{1}$ and Hiroshi Imai ${ }^{1}$ \\ ${ }^{1}$ Laboratory of Reproductive Biology, Graduate School of Agriculture, Kyoto University, Kyoto 606-8502, Japan; ${ }^{2}$ Division of \\ Human Genetics, Department of Integrated Genetics, National Institute of Genetics, Research Organization of Information \\ and Systems, Mishima 411-8540, Japan; ${ }^{3}$ Department of Genetics, School of Life Science, The Graduate University for \\ Advanced Studies (SOKENDAI), Mishima 411-8540, Japan; ${ }^{4}$ Laboratory of Plant Pathology, Graduate School of Agriculture, \\ Kyoto University, Kyoto 606-8502, Japan
}

\begin{abstract}
Small RNAs ranging in size between 18 and 30 nucleotides (nt) are found in many organisms including yeasts, plants, and animals. Small RNAs are involved in the regulation of gene expression through translational repression, mRNA degradation, and chromatin modification. In mammals, microRNAs (miRNAs) are the only small RNAs that have been well characterized. Here, we have identified two novel classes of small RNAs in the mouse germline. One class consists of $~ 20$ - to 24-nt small interfering RNAs (siRNAs) from mouse oocytes, which are derived from retroelements including LINE, SINE, and LTR retrotransposons. Addition of retrotransposon-derived sequences to the $3^{\prime}$ untranslated region (UTR) of a reporter mRNA destabilizes the mRNA significantly when injected into full-grown oocytes. These results suggest that retrotransposons are suppressed through the RNAi pathway in mouse oocytes. The other novel class of small RNAs is 26- to 30-nt germline small RNAs (gsRNAs) from testes. gsRNAs are expressed during spermatogenesis in a developmentally regulated manner, are mapped to the genome in clusters, and have strong strand bias. These features are reminiscent of Tetrahymena $\sim 23$ - to 24-nt small RNAs and Caenorhabditis elegans X-cluster small RNAs. A conserved novel small RNA pathway may be present in diverse animals.
\end{abstract}

[Keywords: Small RNA; siRNA; miRNA; retrotransposon; gsRNA; piwi]

Supplemental material is available at http://www.genesdev.org.

Received March 3, 2006; revised version accepted May 11, 2006.

RNA interference (RNAi) is a sequence-specific gene regulatory mechanism conserved among diverse eukaryotes. The sequence specificity in RNAi is determined by a family of 18- to 30-nucleotide (nt) regulatory small RNAs (for review, see Aravin and Tuschl 2005). Two major classes of endogenous small RNAs have been characterized: microRNAs (miRNAs) and small interfering RNAs (siRNAs). miRNAs-the best-characterized endogenous small RNAs in eukaryotes-have been identified in diverse plants and animals, and are mainly involved in development and differentiation. miRNAs are

\footnotetext{
${ }^{5}$ Present address: Department of Art and Science, The University of Tokyo, Tokyo 153-8502, Japan.

${ }^{6}$ Corresponding author.

E-MAIL toshwata@lab.nig.ac.jp; FAX 81-55-981-6800.

Article published online ahead of print. Article and publication date are

online at http://www.genesdev.org/cgi/doi/10.1101/gad.1425706.
}

processed from miRNA precursors (pre-miRNAs) with a stem-loop structure and regulate gene expression through translational repression or mRNA cleavage (for reviews, see Ambros 2004; Bartel 2004; He and Hannon 2004; Du and Zamore 2005). siRNAs are generated from long double-stranded RNA (dsRNA) and are mainly involved in defense against molecular parasites including viruses, transposons, and transgenes through RNAi (Sijen and Plasterk 2003; Shi et al. 2004). Endogenous siRNAs have been classified into at least three subclasses: repeat-associated siRNAs (rasiRNAs), trans-acting siRNAs (ta-siRNAs), and siRNAs derived from natural antisense transcripts (nat-siRNAs) (Lippman and Martienssen 2004; Peragine et al. 2004; Borsani et al. 2005). rasiRNAs corresponding to repetitive elements repress the repeat sequences at the transcriptional or post-transcriptional level and maintain a centromeric heterochromatic 
structure (Lippman and Martienssen 2004). rasiRNAs have been cloned and sequenced in Schizosaccharomyces pombe, Trypanosoma brucei, Caenorhabditis elegans, Drosophila melanogaster, Danio rerio, and Arabidopsis thaliana, but not in mammals (for review, see Aravin and Tuschl 2005). In D. melanogaster and $D$. rerio, however, the lengths of rasiRNAs are longer than those of miRNAs (Ambros et al. 2003; Chen et al. 2005). ta-siRNAs are processed from dsRNAs synthesized by an endogenous RNA-dependent RNA polymerase $(\mathrm{RdRp})$ utilizing endogenous mRNAs as template (Peragine et al. 2004). nat-siRNAs are processed from dsRNAs formed between endogenous sense and antisense transcripts (Borsani et al. 2005).

In addition to miRNA and siRNA, several classes of small RNAs have been reported. scanRNAs (scnRNAs; 27-30 nt) in Tetrahymena thermophila are thought to be derived from dsRNA precursors and guide DNA elimination (Mochizuki et al. 2002; Lee and Collins 2006). small RNAs (23-24 nt) in T. thermophila are mapped to the genome in clusters and are oriented in the same direction (Lee and Collins 2006). X-cluster small RNAs in C. elegans are derived from a locus on Chromosome $\mathrm{X}$ extending $\sim 2 \mathrm{~kb}$ and are oriented in the same direction (Ambros et al. 2003). Several factors including DCR-1, Dicer-related helicase DRH-1, the RdRp RRF-1, and the exonuclease ERI-1 are reported to be required for the accumulation of X-cluster small RNAs (Duchaine et al. 2006). The roles of 23- to 24-nt small RNAs in T. thermophila and X-cluster small RNAs in C. elegans remain unknown.

Key factors required for the biogenesis and function of these small RNAs are Dicer and Argonaute proteins (for review, see Tomari and Zamore 2005). Dicer is an RNaseIII-like enzyme that recognizes dsRNAs, including pre-miRNAs, and processes them into doublestranded small RNAs (Hutvagner et al. 2001). The Dicergenerated double-stranded small RNAs are recruited by Argonaute, and then a strand (called the passenger strand) is released from Argonaute and the other strand (called the guide strand) remains associated with Argonaute as a guide to regulate gene expression (Matranga et al. 2005). Based on the amino acid sequence alignments, the Argonaute protein family has been subdivided into two subfamilies, referred to as the Argonaute and Piwi families (Carmell et al. 2002).

Mice have four Argonaute family genes (AGO1-4) and three Piwi family genes (Miwi, Mili, and Piwil4). AGO14, which are ubiquitously expressed in many tissues ( $\mathrm{Lu}$ et al. 2005), recruit miRNAs (Liu et al. 2004). Piwi family genes are expressed predominantly in male germline cells (Kuramochi-Miyagawa et al. 2001) and have crucial roles in spermatogenesis. Disruption of Miwi causes spermatogenic arrest at the beginning of the round spermatid stage (Deng and Lin 2002). Spermatogenesis in Mili-null mice is blocked completely at the early prophase of the first meiosis (Kuramochi-Miyagawa et al. 2004). The molecular functions and associated small RNAs of Piwi family proteins remain unknown.

Whether endogenous siRNAs are present in mouse is unclear for three reasons: (1) There has been no report of siRNA cloning in mammals; (2) there is no evidence for the presence of RdRp activity in mammals, which generates dsRNAs, namely the precursors of siRNAs; and (3) induction of the interferon pathway by dsRNAs usually results in cell death, suggesting that mammalian cells may not tolerate dsRNAs (Elbashir et al. 2001a). However, in mouse oocytes and preimplantation embryos the interferon response is suppressed, and injection of long dsRNAs results in specific reduction in the amount of target mRNAs (Svoboda et al. 2000; Yan et al. 2005). Furthermore, retrotransposons and their antisense transcripts are expressed in mouse preimplantation embryos (Peaston et al. 2004; Svoboda et al. 2004a), and knockdown of Dicer in mouse preimplantation embryos results in a $50 \%$ increase in IAP and MuERV-L retrotransposons (Svoboda et al. 2004a). These studies suggest that endogenous dsRNA-induced RNAi can occur in mouse oocytes and early embryos.

In mammals, hundreds of miRNAs have been identified by extensive small RNA cloning and bioinformatic analyses (Lagos-Quintana et al. 2001; Houbaviy et al. 2003; Lim et al. 2003). However, other classes of small RNAs have not been studied. In this study, as a step to obtain a whole picture of the small RNA population in mammals, we have cloned and sequenced small RNAs from oocytes and testes. We identified two classes of small RNAs other than miRNAs. One class comprised 22-nt retrotransposon-derived siRNAs in oocytes, which showed characteristics of small RNAs associated with RNAi. The other class comprised novel 26- to 30-nt germline small RNAs (gsRNAs) that were present in male germ cells and had some interesting features that were distinct from those of siRNAs and miRNAs. The features of the two classes of small RNAs suggest their distinct origins and functions and the existence of two separate small RNA pathways in the mouse germline.

\section{Results}

\section{Cloning of small RNAs from the mouse germline}

In order to identify small RNAs expressed in the mouse germline, we constructed small RNA libraries using RNA isolated from oocytes and testes at different stages. We collected prophase I full-grown (FG) oocytes and Metaphase II (MII) oocytes. The seminiferous tubules from 8-d-old mouse testes contain only spermatogonia and somatic cells (Bellve et al. 1977). At day 10 after birth, some spermatogonia start to enter meiotic prophase. Secondary spermatocytes and spermatids appear at day 18-20. We obtained 8-d-old (spermatogonia and somatic cells), 15-d-old (from spermatogonia to pachytene spermatocytes and somatic cells), and adult testes (from spermatogonia to spermatozoa and somatic cells). We noticed that RNA extracted from the testes of adult mice contained an abundant population of small RNAs $\sim 30 \mathrm{nt}$ long that were apparently longer than miRNAs (Fig. 1). Therefore, we made small RNA libraries by ex- 


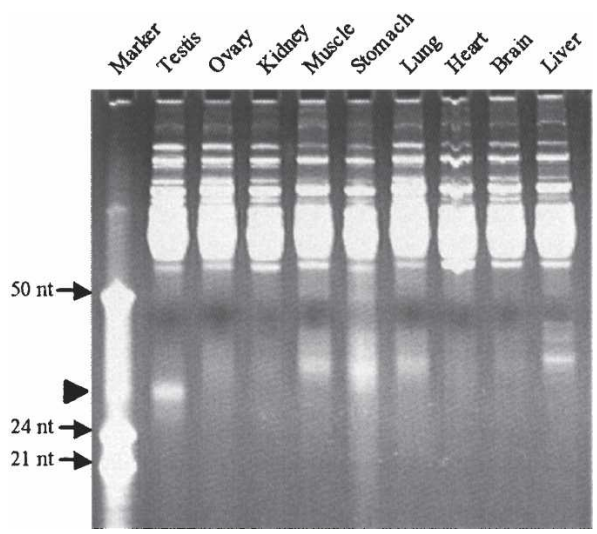

Figure 1. Unidentified $\sim 30$-nt small RNA in testis. Total RNA was enriched by PEG 6000 solution for low-molecular-weight RNA from various tissues. Approximately 20 micrograms of low-molecular-weight RNA was loaded on a $15 \%$ acrylamide gel and stained using ethidium bromide. An $\sim 30$-nt RNA band is observed in testis as indicated by an arrowhead.

cising a portion of a polyacrylamide gel containing 16to 32-nt small RNAs.

\section{Small RNAs in oocytes}

We sequenced a total of 395 clones from oocytes. No clear difference was observed between the small RNA profiles of FG and MII oocytes (Table 1). Of these, 247 clones $(63 \%)$ were mapped to the mouse genome, which included breakdown products of noncoding RNAs (rRNAs, tRNAs, snRNAs, snoRNAs, and pseudogene RNAs; $37.5 \%)$, miRNAs $(10 \%)$, rasiRNAs $(11 \%)$, and small RNAs matched to mRNAs (2\%). We identified 39 clones of miRNAs derived from seven miRNA genes (Supplementary Table S1; Supplementary Fig. S1). We cloned seven small RNAs that matched mRNAs, of which five were derived from the sense orientation and two from the antisense orientation. Furthermore, we cloned two small RNAs that matched the Au76 pseudogene, which was located in the imprinted locus of $I g f 2 r$ and antisense to the Air noncoding transcript that is required for imprinting of Igf2r genes (Lyle et al. 2000; Sleutels et al. 2002). The unknown small RNAs that did not match the genome represented $19 \%$ in the small RNA library. This class of small RNAs might be derived from unidentified bacteria or yeasts, or could result from sequence errors.

We identified 43 clones of rasiRNAs representing 40 different sequences. The 40 unique rasiRNAs were from 11 different retrotransposons (LINE, SINE, and LTR retrotransposons) but not from DNA transposons (see below; Supplementary Table S2). It has been reported that retrotransposons occupy $\sim 13 \%$ of the expressed sequence tags (ESTs) in FG oocytes (Peaston et al. 2004). In our small RNA library, in contrast, rasiRNAs constituted $41 \%$ of pol II transcript-derived small RNAs (miRNAs, rasiRNAs, gsRNAs [see later], other small RNAs derived from ncRNAs, and mRNAs and unknown small RNAs that matched the genome). This value was significantly higher than that of the retrotransposon-derived ESTs $(p<0.01$; Student's two-tailed $t$-test), suggesting that retrotransposons are actively processed to small RNAs.

\section{Characteristics of rasiRNAs in oocytes}

To investigate whether the rasiRNAs are indeed siRNAs, we examined their length and first nucleotide. rasiRNAs in oocytes showed a tight size distribution between 20 and $23 \mathrm{nt}$ with an average of $21.9 \mathrm{nt}$ (SD = $1.3 \mathrm{nt})$, similar to that of miRNAs $(21.4 \pm 1.24 \mathrm{nt}$; mean $\pm \mathrm{SD}$ ), which are processed by Dicer (Supplementary Table S3). This size distribution and mean length were clearly different from those of, for example, the breakdown product of tRNAs $(26.4 \pm 5.09 \mathrm{nt})$. In addition, rasiRNAs in oocytes showed a strong preference for uridine and adenine residues at the first position (79\%) compared with rRNAs $(21 \%)$ or tRNAs $(45 \%)$ (Supplementary Table S4). This preference was consistent with the trend observed in miRNAs $(86 \%)$ and functional siRNAs (Aravin et al. 2003; Khvorova et al. 2003). Furthermore, rasiRNAs in oocytes were mapped to both sense (24 clones) and antisense (19 clones) orientations of

Table 1. Number (\%) of small cDNAs cloned from mouse oocytes and testes

\begin{tabular}{|c|c|c|c|c|c|c|c|c|}
\hline \multirow[b]{2}{*}{ Type } & \multicolumn{2}{|c|}{ Stage of oocytes } & \multirow[b]{2}{*}{ Subtotal } & \multicolumn{3}{|c|}{ Stage of testes (days after birth) } & \multirow[b]{2}{*}{ Subtotal } & \multirow[b]{2}{*}{ Total } \\
\hline & FG & MII & & $8 \mathrm{~d}$ & $15 \mathrm{~d}$ & Adult & & \\
\hline miRNA & $18(16)$ & $21(7)$ & $39(10)$ & $55(21)$ & $146(32)$ & $69(17)$ & $270(24)$ & $309(21)$ \\
\hline rasiRNA & $12(11)$ & $31(11)$ & $43(11)$ & $9(3)$ & $18(4)$ & $19(5)$ & $46(4)$ & $89(6)$ \\
\hline Germline small RNA (gsRNA) & $2(2)$ & & $2(0.5)^{\mathrm{a}}$ & & $147(33)$ & $234(59)$ & $381(34)$ & $383(25)$ \\
\hline rRNA & $20(18)$ & $69(24)$ & $89(23)$ & $26(10)$ & $16(4)$ & $4(1)$ & $46(4)$ & $135(9)$ \\
\hline tRNA & $18(16)$ & $36(13)$ & $54(14)$ & $110(42)$ & $35(8)$ & $18(5)$ & $163(15)$ & $217(14)$ \\
\hline Other ncRNA ${ }^{\mathrm{b}}$ & & $2(0.7)$ & $2(0.5)$ & $3(1)$ & $1(0.2)$ & $1(0.3)$ & $5(0.5)$ & $7(0.5)$ \\
\hline mRNA & $2(2)$ & $5(2)$ & $7(2)$ & $8(3)$ & $15(3)$ & $6(2)$ & $29(3)$ & $36(2)$ \\
\hline Bacterium/yeast & $14(13)$ & $57(20)$ & $71(18)$ & $4(2)$ & & $2(0.5)$ & $6(0.5)$ & $77(5)$ \\
\hline Unknown (matched to the genome) & $5(5)$ & $6(2)$ & $11(3)$ & $6(2)$ & $24(5)$ & $24(6)$ & $54(5)$ & $65(4)$ \\
\hline Unknown & $20(18)$ & $57(20)$ & 77 (19) & $41(16)$ & $48(11)$ & $22(6)$ & $111(10)$ & $188(12)$ \\
\hline Total & $111(100)$ & $284(100)$ & $395(100)$ & $262(100)$ & $450(100)$ & $399(100)$ & $1111(100)$ & $1506(100)$ \\
\hline
\end{tabular}

This class of small RNAs was mapped to the loci where testis gsRNAs were clustered.

b This type includes small RNA derived from snRNA, snoRNA, and a pseudogene. 
retrotransposons (Fig. 2A). These findings suggest that the rasiRNAs in oocytes are siRNAs processed from inter- or intramolecular dsRNAs.

\section{Retrotransposon-derived sequences destabilize mRNA}

From FG and MII oocytes, we cloned a total of 43 siRNAs, which were derived from L1 (12 clones), MTA (eight clones), RLTR10 (six clones), IAP1 (five clones), and others (12 clones) (Supplementary Table S2.). Retrotransposons are reportedly expressed in a developmentally regulated manner in mouse oocytes and early embryos (Peaston et al. 2004). L1, MTA, and IAP1 were expressed in FG oocytes, and RLTR10 was selectively expressed in growing oocytes (Herrera et al. 2005). To investigate whether these retrotransposons are posttranscriptionally regulated in FG oocytes, we inserted L1, MTA, and IAP1 sequences encompassing the siRNAs (Fig. 2A) into the $3^{\prime}$ untranslated region (UTR) of EGFP mRNA. These chimeric mRNAs were microinjected into FG oocytes, and the amounts were measured at $16 \mathrm{~h}$ and $40 \mathrm{~h}$ after injection. As controls, $\sim 600$ base pairs (bp) of the 3' UTR of $\beta$-actin mRNA and $\sim 40$ bp of the vector backbone sequence were respectively inserted into the same position of EGFP mRNA. All of the EGFP-retrotransposon mRNAs were degraded significantly more $(P<0.05$; Dunnet $)$ compared with EGFP alone, EGFPactin, and EGFP-vector mRNA at $40 \mathrm{~h}$ (Fig. 2B). To investigate whether the instability observed here was caused by an RNAi mechanism or other mechanisms such as those involving sequence-specific RNA-binding proteins (Paillard et al. 1998; Surdej and Jacobs-Lorena 1998), antisense strands of retrotransposons were inserted into EGFP mRNA and its degradation was examined at $16 \mathrm{~h}$ after injection. All of these EGFP-retrotransposons (antisense) underwent more degradation $(P<0.05$; Dunnet $)$ than EGFP mRNA, as was the case for the sense strands (Fig. 2C). These results are consistent with the hypothesis that retrotransposons are post-transcriptionally regulated in mouse FG oocytes by an RNAi mechanism.

\section{Small RNAs in testis}

We sequenced a total of 1111 clones from testes at three stages: $8 \mathrm{~d}$ (262 clones), $15 \mathrm{~d}$ (450 clones), and adult (399 clones; Table 1). Of the 1111 clones, 994 clones $(90 \%)$ matched sequences in the mouse genome, which included breakdown products of noncoding RNAs (rRNA, tRNA, snRNA, snoRNA, and pseudogene; 20\%), miRNAs $(24 \%)$, and rasiRNAs $(4 \%)$. We identified 270 clones of miRNAs representing 52 kinds of miRNAs, which included six novel miRNAs. We then confirmed expression of the six miRNAs by Northern blotting (Supplementary Table S5; Supplementary Fig. S1). Of the novel miRNAs, four miRNAs (miR-741, miR-742, miR-743, and $\mathrm{miR}-465-3 \mathrm{p}$ ) were mapped to the genome in a $62-\mathrm{kb}$ region on the $\mathrm{X}$ chromosome (Supplementary Fig. S1). miR-463, miR-465-5p, miR-470, and miR-471, which were reported to be expressed in testes (Yu et al. 2005), were also mapped to the same region. In view of the previous findings on other miRNAs (Lagos-Quintana et al. 2001; Lau et al. 2001; Houbaviy et al. 2003), some or all of these eight miRNAs may be transcriptionally regulated in a polycistronic manner. We identified 46 clones of rasiRNAs representing 44 different sequences (Supplementary Table S6). The rasiRNAs identified were from 11 different retrotransposons, but not from DNA transposons. This specific association with retrotransposons is the same as that of rasiRNAs in mouse oocytes, but the rasiRNAs identified in testes had different lengths $(p<0.01 ; t$-test $)$ and orientations than those in oocytes (Supplementary Table S6). This suggests that rasiRNAs in testes represent a class of small RNAs that is
A

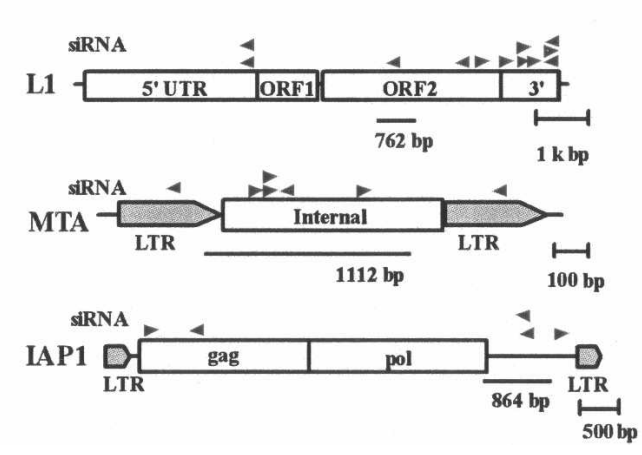

B

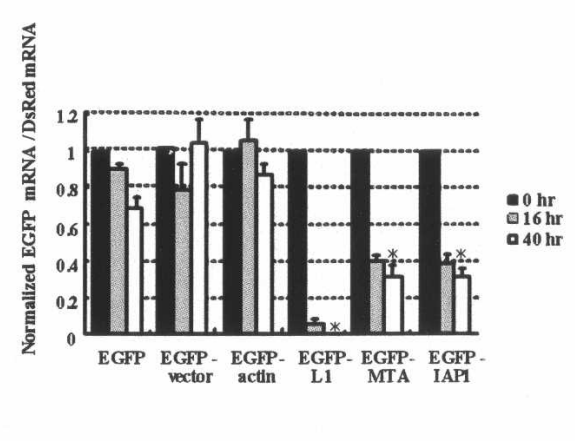

C

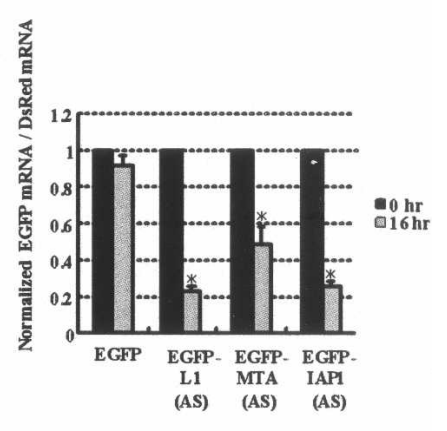

Figure 2. Degradation of EGFP mRNA with retrotransposon-derived sequences. $(A)$ Retrotransposons are schematically represented, and rasiRNAs are mapped. Arrowheads indicate the positions and orientation of the rasiRNAs cloned from an oocyte small RNA library. The bars under the retrotransposons show the sequences inserted into the EGFP 3' UTR. $(B)$ EGFP, EGFP-retrotransposon, EGFP-vector, or EGFP- $\beta$-actin 3' UTR mRNA was coinjected with DsRed mRNA into mouse FG oocytes. After $0 \mathrm{~h}, 16 \mathrm{~h}$, and $40 \mathrm{~h}$ of injection, five to 10 oocytes were collected and the injected mRNAs were quantified by RT-PCR. The amount of EGFP was normalized to that of DsRed and then normalized again to that obtained at $0 \mathrm{~h}$ in each case $(n=5$; error bars indicate SE). The amounts of EGFP-retrotransposon mRNAs differed significantly from that of EGFP, EGFP-vector, and EGFP-actin mRNAs at $40 \mathrm{~h}$. $\left({ }^{\star}\right) P<0.05$ (Dunnet). $(C)$ Insertion of the antisense retrotransposon sequence also reduced mRNA amount $(P<0.05$; Dunnet). 
Watanabe et al.

different from the rasiRNAs in oocytes /see the following section).

\section{A novel class of 26- to 30-nt small RNAs in testes}

Most of the remaining sequences from testes were mapped to the genome in clusters (Fig. 3). Statistically significant clustering was confirmed at 34 loci (Supplementary Data S1; Supplementary Table S7). In these 34 clusters, a total of 381 small RNAs were mapped, and each cluster included two to 82 clones (Supplementary Table S7). These small RNAs were mapped to the genome in clusters with strand bias (Fig. 3). Most of these loci were in intergenic regions in the genome and have not been characterized yet, while some loci overlapped with known or hypothetical protein-coding genes in the sense or antisense orientation. Most (86\%) of the first nucleotides of these small RNAs were uridine, as is the case with miRNAs (76\% uridine) (Supplementary Table S4), but the mapped regions covering these clones were not folded into the stem-loop structure that is characteristic of miRNA precursors. It has been reported that one strand of siRNA duplexes is recruited by AGO, depend- ing on the asymmetry of internal stability of siRNA (Khvorova et al. 2003; Schwarz et al. 2003). No fixed asymmetry pattern was observed for these small RNAs (data not shown), suggesting that such asymmetry does not account for the strand bias. The mean length of these small RNAs $(27 \pm 2.97 \mathrm{nt})$ was quite different from that of miRNAs $(21.4 \pm 1.24 \mathrm{nt})$ and rasiRNAs in oocytes $(21.9 \pm 1.3 \mathrm{nt})$ (Supplementary Table S3). The abovementioned 381 clones comprised 357 independent sequences, and some of these small RNAs overlapped each other, revealing a high complexity of the small RNA population (Supplementary Table S7). Their sequences and genome mapping data did not match those of any previously described small RNAs. We therefore named these testes "germline small RNAs" (gsRNAs) (listed in Supplementary Table S7).

As described in the previous section, a total of 46 rasiRNAs were cloned in testis, the most prominent classes being IAP (16 clones), B1 (13 clones), and L1 (five clones) (Supplementary Table S6). The mean length and first nucleotide of rasiRNAs in testes $(25.5 \pm 4.53 \mathrm{nt}$; $\mathrm{U}$ : $80 \%$ ) were similar to those of gsRNAs (Supplementary Tables S3, S4), but apparently different from those of
gsRNA cluster on AC113269 (gsRNA 243 259)
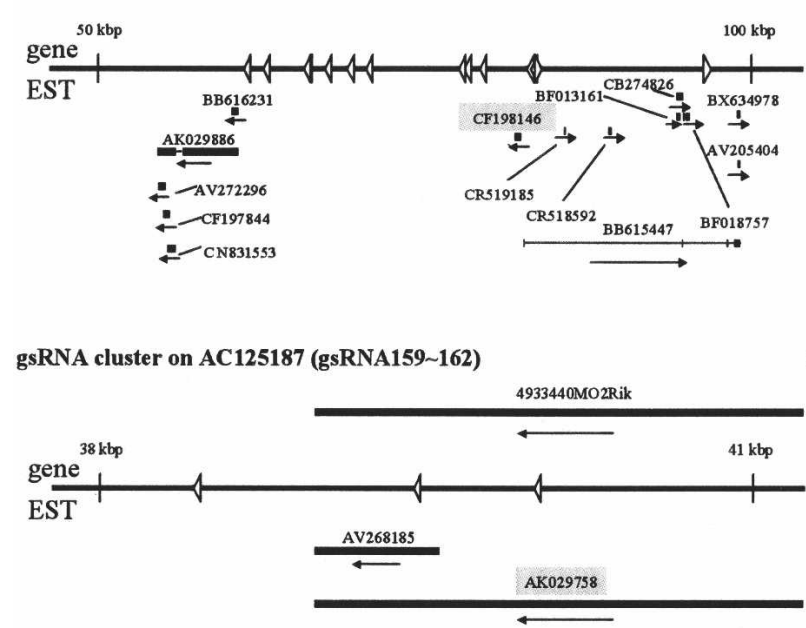

gsRNA cluster on AC153373 (gsR NA 97-98)

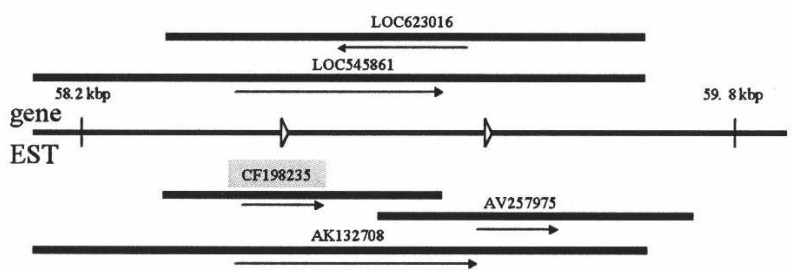

gsRNA cluster on AC125141 (gsRNA278 359)

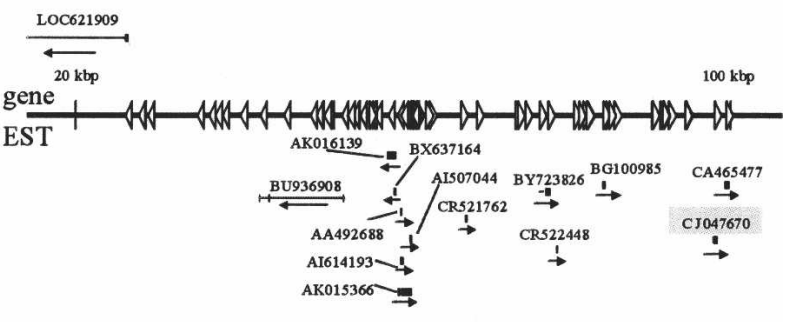

gsRNA cluster on AC130548 (gsRNA46 71)

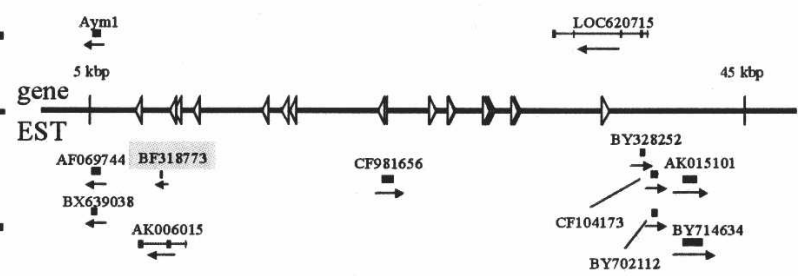

Figure 3. Genomic organization of gsRNA clusters. The arrowheads on the genomic DNA denote the orientation and location of each gsRNA. The black bars and arrows above or below the genomic DNA denote the locations and orientations of genes and ESTs in the cluster. Genes are at the top and ESTs are at the bottom. The clusters on AC113269, AC125141, and AC130548 are intergenic regions. The cluster on AC125187 overlaps a hypothetical protein-coding gene in the same direction. The cluster on AC153373 overlaps two hypothetical protein-coding genes. Among them, LOC545861 is in the same direction as the cluster, and LOC623016 is in the opposite direction to the cluster. We did not detect LOC623016 transcripts in testes (Fig. 6C, AC153373, sense primer RT). ESTs with highlighted accession numbers denote the cDNAs that were examined in Figure 6 by RT-PCR. 
rasiRNAs in oocytes $(21.9 \pm 1.3 \mathrm{nt}$; U: $51 \%)$. Northern blot analysis using B1 and IAP probes revealed $\sim 30 \mathrm{nt}$, $\sim 26 \mathrm{nt}$ (both IAP and B1), and $22 \mathrm{nt}$ (only B1) bands (Supplementary Fig. S2). Furthermore, an orientation bias was observed in testes rasiRNAs: All IAP small RNAs (16 clones) were derived from the antisense strand, and all B1 small RNAs (13 clones) and all L1 small RNAs (five clones) were from the sense strand (Supplementary Table S6). These data suggest that the biogenesis of rasiRNAs in testes is different from that in oocytes and that gsRNAs and rasiRNAs are generated through the same pathway in testes.

gsRNA has a 5' phosphate group and a 3' hydroxyl group

Upon an electrophoretic separation of RNA from adult male testes, gsRNAs appeared as a single band at $\sim 30 \mathrm{nt}$ (Fig. 1). The RNA from this band was degraded by RNase treatment but not by DNase, showing that gsRNAs are indeed RNA (Fig. 4A). T4-RNA ligase catalyzes ligation of a 5' phosphoryl-terminated RNA to a 3' hydroxylterminated RNA through the formation of a phosphodiester bond. The addition of ligase resulted in the production of concatemerized RNA species that migrated slower than the untreated band (Fig. 4B). The concatemerized bands were not observed when treated by alkaline phosphatase (CIAP) before treatment with ligase. These results indicate that gsRNAs contain a $5^{\prime}$ phosphate group and a 3 ' hydroxyl group like other functional small RNAs (Elbashir et al. 2001b; Mochizuki et al. 2002).

\section{gsRNAs are expressed during spermatogenesis}

Of nine adult mouse tissues examined, only the testes expressed the $\sim 30$-nt RNA species (Fig. 1). The testesspecific expression was confirmed by Northern blotting using probes complementary to five individual gsRNAs (Fig. 5A). gsRNAs were detected in testes from a wildtype mouse, but not in testes from a $\mathrm{W}^{\mathrm{V}} / \mathrm{W}^{\mathrm{V}}$ mouse, in which germ cell differentiation is arrested at spermato-
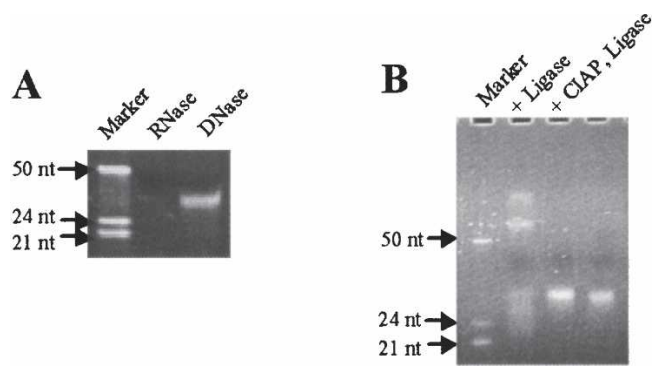

Figure 4. Molecular characterization of gsRNAs. (A) gsRNAs were gel purified and treated with RNaseA or DNaseI. After the treatment, RNA was electrophoresed on a denaturing $15 \%$ acrylamide gel and visualized by ethidium-bromide staining. (B) gsRNAs were incubated with or without CIAP and then treated with T4 RNA ligase. The right-most lane is untreated gsRNAs.
$\mathbf{A}$
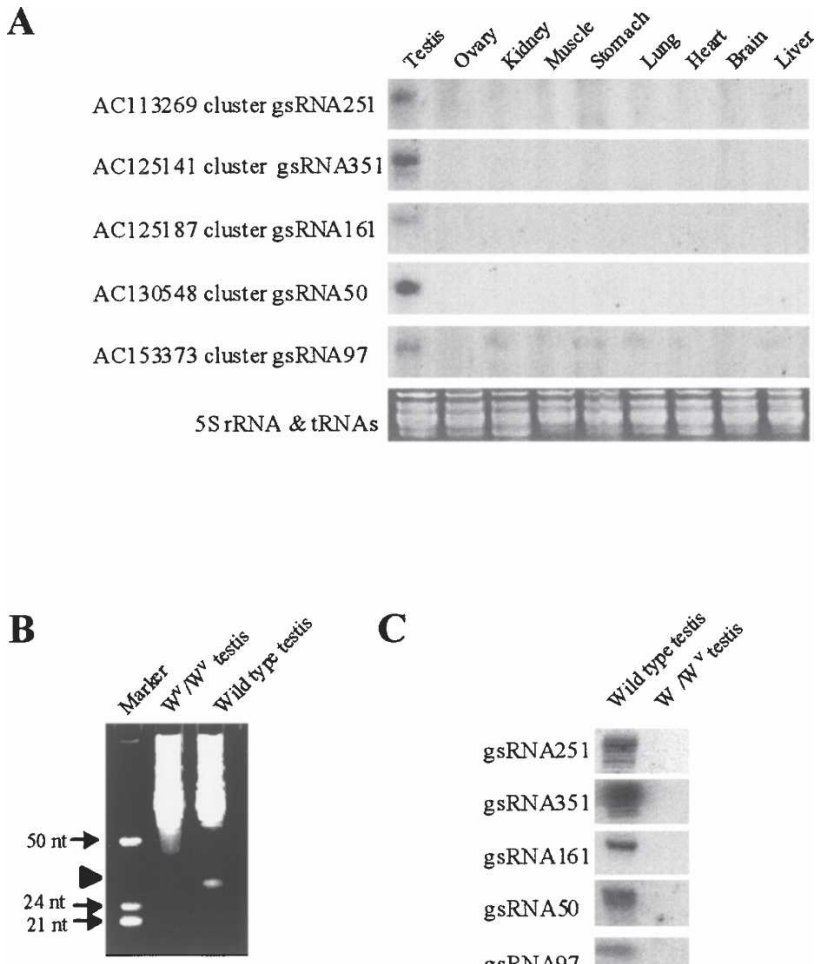

C

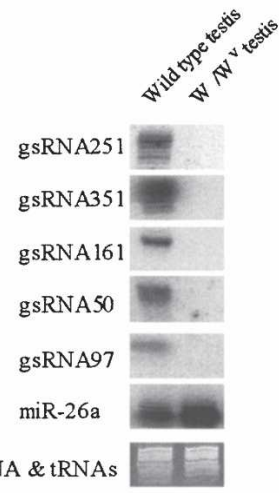

D

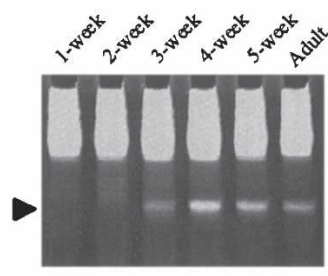

$\mathbf{E}$

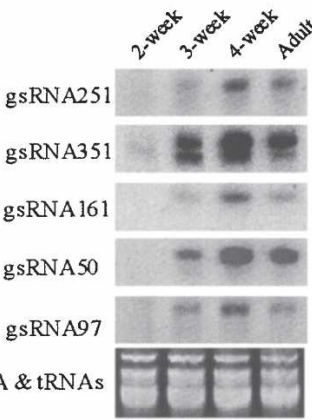

gsRNA341

5S rRNA \& tRNAs

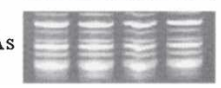

Figure 5. Expression of gsRNAs. $(A, C, E)$ Low-molecularweight RNA $(20 \mu \mathrm{g})$ from various tissues $(A)$, testes of $\mathrm{W} / \mathrm{W}^{\mathrm{V}}$ and wild-type mice $(C)$, and testes at different stages $(E)$ was probed for individual gsRNAs. Accession numbers of the clusters are shown on the left in A. gsRNA341 and gsRNA351 are from the same cluster. Equal loading was confirmed by ethidium-bromide staining of 5SrRNA and tRNAs. $(B, D)$ Total RNA $\left(50 \mu \mathrm{g}\right.$ ) from testis of wild-type and $\mathrm{W}^{\mathrm{V}} / \mathrm{W}^{\mathrm{V}}$ mutant mice $(B)$ and wild-type testes at different stages $(D)$ was loaded on a $15 \%$ acrylamide gel and stained with ethidium bromide. gsRNAs appear as a band located at $\sim 30 \mathrm{nt}$ (arrowhead).

gonia (Fig. 5B,C; Handel and Eppig 1979), suggesting that gsRNAs were expressed in more differentiated germ cells. 
Cloning efficiencies of gsRNAs dramatically changed among developmental stages: $0 \%$ at $8 \mathrm{~d}, 33 \%$ at $15 \mathrm{~d}$, and $59 \%$ at an adult stage (Table 1). This indicates that expression of gsRNAs is developmentally regulated during spermatogenesis. Indeed, gsRNAs were detected in testes from 3 wk to adult, but not in testes from 1 and $2 \mathrm{wk}$ (Fig. 5D). Northern blotting data of five individual gsRNAs showed the same patterns (Fig. 5E). Expression of these gsRNAs started at $\sim 3 \mathrm{wk}$, peaked at $4 \mathrm{wk}$, and declined in adults. In testes of 2- to 3-wk-old mice, pachytene spermatocytes become abundant. Round spermatids become abundant in 3- to 4-wk-old mice, and adult testes contain all the cell types, including abundant elongated spermatids (Bellve et al. 1977). Thus, the data indicate that gsRNAs are expressed from the pachytene spermatocyte stage to the round spermatid stage during spermatogenesis.

Interestingly, Northern blotting for gsRNA341 and gsRNA351 showed a $\sim 26-\mathrm{nt}$ band in addition to the $\sim 30$ nt band (Fig. 5E). A faint $~ 26-n t$ band was also observed in 2-wk-old testes. As for gsRNA351, the $~ 26$-nt band was as abundant as the $\sim 30-n t$ band at $3 \mathrm{wk}$, but in adults the main class was $\sim 30-n t$ RNAs. In agreement with the existence of two size classes of gsRNAs, the gsRNAs cloned from 15-d-old mice were shorter $(26.0 \mathrm{nt})$ and more broadly distributed ( $\mathrm{SD}=3.41 \mathrm{nt}$ ) than the gsRNAs cloned from adults $(27.7 \pm 2.43 \mathrm{nt})$ (Supplementary Table S3). In addition, the size of the most abundantly cloned class was $26 \mathrm{nt}$ in 15-d-old mice and $30 \mathrm{nt}$ in adults, suggesting that the gsRNA biogenesis pathway is complex.

\section{Primary transcripts of gsRNAs}

Some ESTs were mapped to the loci where gsRNAs were clustered. Interestingly, most of these transcripts were cloned from testes and were oriented in the same direction as gsRNAs (Fig. 3). RT-PCR analysis of five of these transcripts also revealed testis-specific expression (Fig. 6A; for transcripts examined, see Fig. 3). Furthermore, their expression in testes preceded that of gsRNA by $1 \mathrm{wk}$ and changed with development in the same manner as gsRNAs (Fig. 5D). Thus, the ESTs were first detected at $2 \mathrm{wk}$, peaked at $3 \mathrm{wk}$, and declined in adults

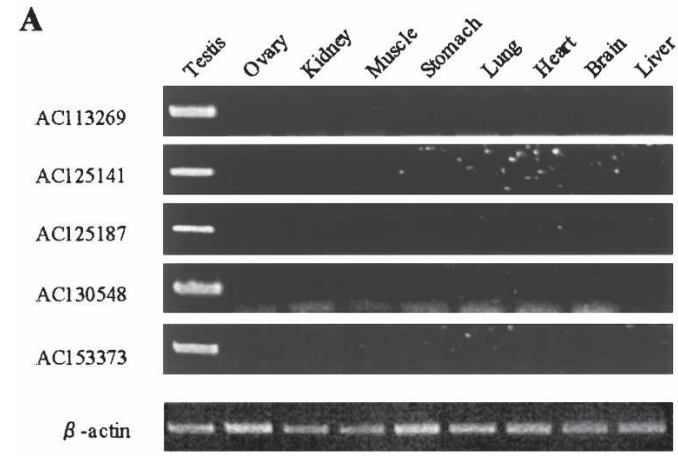

C

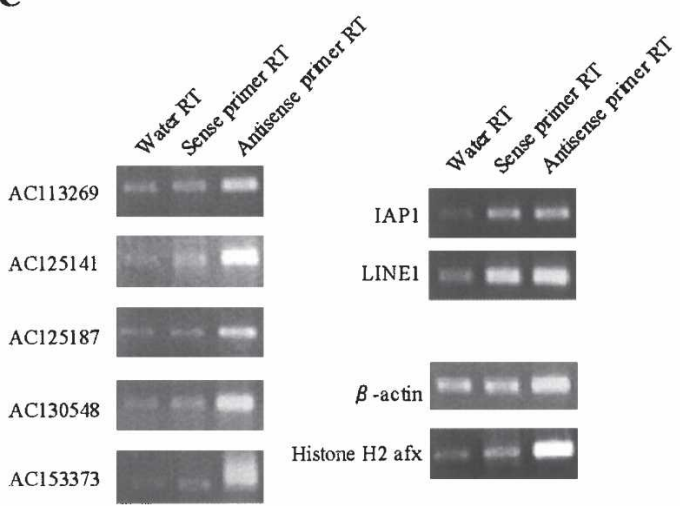

B

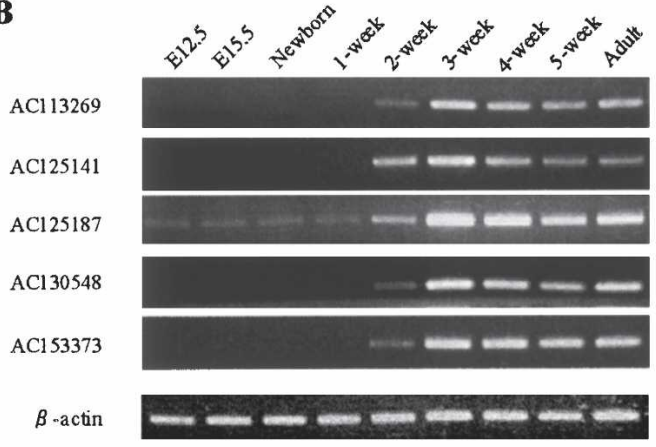

D

\begin{tabular}{clcc}
\hline Order & \multicolumn{1}{c}{ Consensus Motif } & \multicolumn{2}{c}{ Precursors } \\
with consensus & E-value \\
\hline 1 & AGGAAAAAAAAAAAA & 10 & $5.3 \mathrm{e}^{-11}$ \\
2 & CCCTGCTCCTGCCTC & 15 & $5.9 \mathrm{e}^{-4}$ \\
3 & CATGGCTCAGCTCACCAGACATG & 3 & $6.6 \mathrm{e}^{-2}$ \\
& ACATCTGGAGCCGGATCCTCCTG & 15 & $3.1 \mathrm{e}^{+0}$ \\
4 & TCCCTGGG & 6 & $1.0 \mathrm{e}^{+1}$ \\
5 & GACCACCACTGCGAGCCTGCCGGACA & 6 & \\
\hline
\end{tabular}

Figure 6. Analysis of putative gsRNA precursors. $(A, B)$ Expression of putative gsRNA precursors was analyzed by RT-PCR in various tissues $(A)$ and in testes at different stages $(B)$. Accession numbers of the gsRNA clusters are listed on the left. The examined ESTs are indicated in Figure 3. $(C)$ Strand-specific expression of putative gsRNA precursors. Total RNA from adult mouse testes was reversetranscribed with no primer, with a gene-specific sense primer, or with a gene-specific antisense primer, and then PCR was performed using a set of gene-specific primers. Accession numbers of the gsRNA clusters and the examined ESTs are as in $A$ and $B$. Retrotransposons (IAP1 and LINE1) and protein-coding genes ( $\beta$-actin and Histone $\mathrm{H} 2$ afx) serve as a positive and a negative control for the existence of antisense transcripts, respectively. $(D)$ Overrepresented motifs in the putative gsRNA precursors are shown. The motif discovery tool MEME was used to search for consensus motifs in all 18 putative gsRNA precursor sequences. The numbers of the gsRNA precursors that contained the consensus motif and E-values are also shown. 
(Fig. 6B). Collectively, these data suggest that the EST transcripts that we examined are the precursor molecules of the gsRNAs.

The extreme strand bias in the production of gsRNAs unlinked to stem-loop structure suggests that the biogenesis pathway of gsRNAs is distinct from that of miRNAs and siRNAs. In support of this suggestion, we did not detect antisense transcripts of these five transcripts by RT-PCR in 3-wk-old and adult testes (Fig. 6C; data not shown). To see if gsRNA precursors contain common secondary structures or motifs, we first BLASTed all of the gsRNAs against the EST databases and obtained putative gsRNA precursor sequences. Most of these sequences had been cloned from testes, but some were from brain or other tissues. Of these, we analyzed the sequences of all 18 cDNA clones that were obtained from testes (Supplementary Table S8). The secondary structures of the putative precursor sequences, as predicted by Mfold version 3.2 (Zuker 2003), did not contain stem-loop structures, intramolecular dsRNA, or other common secondary structures around the gsRNAs. The motif discovery tool MEME (Bailey and Elkan 1994) found a consensus sequence, a 15-nt stretch of adenosine residues (including two guanosine residues), in the internal regions of 10 sequences (Fig. 6D). Some putative precursor sequences had longer poly(A) tracts. A search of 18 randomly selected mRNAs failed to find the poly(A) motif (data not shown). Usually, SINE and LINE retrotransposons contain a $3^{\prime}$ poly(A) tract in their genomic sequences, which is characteristic of retrotransposal integration (Maestre et al. 1995). To investigate whether putative gsRNA precursors contain retrotransposon sequences, we used the Repeat Masker program. Of the 18 precursor sequences that we examined, SINE sequences were observed in six precursors, LINE sequences in five precursors, and LTR retrotransposon sequences in four precursors (Supplementary Table S8). A search of 18 randomly selected full-length EST sequences failed to find such high numbers of retrotransposon sequences (mean $=1, p<0.01 ; t$-test). Partial retrotransposon sequences were abundantly observed in putative gsRNA precursors.

\section{Discussion}

In mammals, miRNAs are the only small RNAs that have been studied in detail. In this study, we identified two classes of small RNAs in the mouse germline through cloning and sequencing of the small RNAs of a broad size distribution. One of these classes is siRNAs in oocytes and the other is gsRNAs in testes. The unique features of the two classes of small RNAs reveal that the pathways and functions of small RNAs in mouse are more diverse than was previously known.

\section{Regulation of retrotransposons through RNAi in mouse oocytes}

Little is known about endogenous siRNAs in mammals, even though they have been extensively studied in other animals and plants. Mammalian cells are not thought to have endogenous siRNAs, which are processed from dsRNAs, because dsRNAs >30 nt in length induce the interferon pathway, leading to cell death (Elbashir et al. 2001a). However, we suspected that functional endogenous siRNAs are present in mammalian oocytes because mammalian oocytes do not have an interferon response, and also because RNAi induced by exogenous long dsRNAs has been observed in mouse oocytes (Svoboda et al. 2000; Yan et al. 2005). As expected, we identified rasiRNAs in mouse oocytes that are likely to be involved in RNAi. They had a bias for uridine at the first nucleotide and a narrow size distribution centered at 22 nt. The identification of rasiRNAs and the instability of chimeric mRNAs containing retrotransposon-derived sequences (Fig. 2) suggest that, in mouse oocytes, retrotransposons are suppressed through RNAi at the posttranscriptional level. In support of this view, an increase of retrotransposon transcripts has been reported in Dicer-deficient embryonic stem (ES) cells and Dicerknockdown preimplantation embryos in mouse (Svoboda et al. 2004a; Kanellopoulou et al. 2005). In addition, rasiRNAs in oocytes may regulate the expression of mRNAs containing retrotransposon-derived sequences. rasiRNAs have a broad range of mRNAs as putative targets. This is because retrotransposons act as the first exon for some genes in oocytes (Peaston et al. 2004), and $18.4 \%$ of the mouse genes contain transposable elements in their untranslated regions (van de Lagemaat et al. 2003).

The RNAi pathway causes epigenetic modifications, such as DNA methylation and histone modification, at loci homologous to the small RNAs in several organisms (Volpe et al. 2002; Zilberman et al. 2003; Grishok et al. 2005). Although siRNA-mediated DNA modification and chromatin remodeling are controversial in mammals (Morris et al. 2004; Park et al. 2004; Svoboda et al. 2004b; Kanellopoulou et al. 2005; Murchison et al. 2005), it is tempting to speculate that differential expression of retrotransposons and subsequent production of siRNAs trigger sequential chromatin remodeling through an RNAi pathway in mouse oocytes and early embryos.

\section{Pathway and function of gsRNAs in testis}

We found a novel class of small RNAs named gsRNAs in mouse testes. gsRNAs are 26- to 30-nt small RNA molecules having features clearly different from those of miRNAs and siRNAs: gsRNAs are longer than miRNAs and siRNAs and have a strand bias unlinked to a stemloop structure. These features suggest that the biogenesis pathway of gsRNAs is different from that of miRNAs and siRNAs. In support of this view, we did not detect the antisense transcripts of gsRNA precursors by RT-PCR or antisense small RNAs of gsRNAs by Northern blotting (Fig. 6C; data not shown). However, we cannot exclude the possibility that gsRNAs are of dsRNA origin, because such precursors may be unstable and therefore cannot be detected. In fact, X-cluster small RNAs in C. elegans, which also show strong strand bias, 
may be of dsRNA origin because their biogenesis requires both DCR-1 and RdRp (Duchaine et al. 2006). On the other hand, we frequently observed retrotransposons in gsRNA precursors. Although the gsRNA biogenesis pathway is unclear, one possibility is that mRNAs that contain retrotransposon-derived sequences in testis are digested by an unidentified enzyme into 26- to 30-nt gsRNAs. Alternatively, gsRNAs may originate from double-stranded RNA-DNA complexes that are produced by the RT enzymes of retrotransposons. Interestingly, the DNA strand of small RNA-DNA complexes is transferred to an archaeal Piwi protein (Ma et al. 2005; Yuan et al. 2005). Piwi family proteins (Miwi, Mili, Piwil4), which are expressed in testis and are required for spermatogenesis, could be involved in the gsRNA pathway.

Expression of gsRNAs was found to be limited to germ cells in testis and limited to the period from the pachytene spermatocyte stage to the early spermatid stage. Northern blotting with the gsRNA341 and gsRNA351 probes showed the existence of $\sim 30$-nt long gsRNAs and 26-nt short gsRNAs (Fig. 5E). Interestingly, the short gsRNAs were faintly detected at $2 \mathrm{wk}$, when the long gsRNAs were not yet detected. These results suggest that gsRNAs occur in two distinct classes and that short gsRNAs are expressed earlier than the long gsRNAs. In support of the existence of both long and short gsRNAs, the sizes of the gsRNAs obtained from 15-d-old testes are shorter than those obtained from adult testes (Supplementary Table S3). The existence of two classes of gsRNAs suggests that two distinct biogenesis pathways with different gsRNA-generating enzymes and gsRNAbinding proteins are present in mouse testis. gsRNAs, which are probably derived from single-stranded RNAs, are unlikely to be transferred to AGO1-4, which are thought to recognize only small RNA duplexes. Interestingly, in mouse testes, the expression patterns of long gsRNAs are very similar to those of Miwi, and the expression of short gsRNAs overlaps with Mili (Kuramochi-Miyagawa et al. 2001). Examination of the association of gsRNAs with Piwi proteins may shed light on the biological roles of gsRNAs in mouse testis.

Most gsRNAs are not complementary to protein-coding mRNAs and not conserved among species. Therefore, they are unlikely to regulate mRNAs in a posttranscriptional manner as miRNAs do. It is important in the future to identify the proteins associated with gsRNAs and to determine the biological processes in which gsRNAs are involved.

\section{Materials and methods}

\section{Small RNA preparation and cDNA library construction}

Total RNA was isolated from C57/B6 mouse testes or oocytes using the guanidium thiocyanate-phenol-chloroform method. Testes were isolated from 8-d-old, 15-d-old, and adult male mice. Females were injected with eCG ( 5 IU) 48 h before oocyte collection, and then FG oocytes were collected from ovaries as described previously (Viveiros et al. 2004). For MII oocytes, females were superovulated by injection of eCG ( $5 \mathrm{IU})$ followed by an injection of hCG (5 IU) $48 \mathrm{~h}$ later, and then oocytes were collected the next morning and incubated in PBS containing 3 $\mathrm{mg} / \mathrm{mL}$ PVP and $0.3 \mathrm{mg} / \mathrm{mL}$ hyaluronidase to remove follicle cells (Nagy et al. 2003). To isolate small RNAs, $50 \mu \mathrm{g}$ of total RNA from testes and $\sim 1.5 \mu \mathrm{g}$ of total RNA ( 1200 oocytes) from oocytes was used. Small RNAs were cloned using the basic protocol (Pfeffer et al. 2005).

\section{Sequence analysis}

To classify small RNAs, we performed NCBI BLASTn searches (http://www.ncbi.nlm.nih.gov) using the default settings. Complexity filtering was used in these BLAST searches, and we chose the "nr" database from all organisms. A small RNA sequence was considered to match the genome if it had no more than two mismatches or if it had a 16-nt stretch of exact match. Most of the sequences were classified in this search. The remaining sequences that were matched to sequences in the mouse genome were then further classified using the following tools or databases: miRNA Registry (http://microrna.sanger .ac.uk/sequences/index.shtml) and Mfold 3.2 (http://www bioinfo.rpi.edu/applications/mfold) for miRNAs; tRNAscan-SE (http://www.genetics.wustl.edu/eddy/tRNAscan-SE) for tRNAs; and Repeat Masker (http://www.repeatmasker.org) and L1Base (http://11base.molgen.mpg.de) for repeat sequences. The small RNAs that were mapped to the mouse genome in clusters and not classified as noncoding RNAs or retrotransposons were classified as gsRNAs. In cases where a small RNA was classified as both gsRNA and mRNA, the small RNA was classified as gsRNA.

To identify gsRNA precursor sequences, all gsRNAs were BLASTed against the "nr" and "est" databases from all organisms, and then the EST sequences cloned from mouse testes were used for further analysis. RNA folding was predicted with Mfold 3.2. After removal of the poly(A) tail, consensus motifs were analyzed by MEME (http://meme.nbcr.net/meme/intro .html) using the "any number of repetition" model. Repeat sequences were analyzed using the Repeat Masker program.

\section{Injection experiments}

A cDNA fragment of EGFP was amplified by PCR from plasmid pd2EGFP-1 (Clontech) using the primers pd2EGFP sense and pd2EGFP antisense (Supplementary Table S9). The amplified fragment was digested with SalI and EcoRI, and ligated to the SalI and EcoRI site of pBlueScript $\mathrm{SK}^{-}$(Stratagene) to construct pBS-EGFP. To insert the retrotransposon-derived sequences or $3^{\prime}$ UTR of $\beta$-actin downstream of the EGFP sequence in pBSEGFP, retrotransposon-derived fragments and the $3^{\prime}$ UTR of $\beta$-actin were amplified using cDNA that was reverse transcribed from mouse MII oocyte RNA using an oligo(dT) primer. The primers used in RT-PCR are listed in Supplementary Table S9. The retrotransposon-derived fragments and 3' UTR of $\beta$-actin were cloned into the pCR4 Blunt-TOPO vector (Invitrogen), and then digested with EcoRI and ligated to the EcoRI site of pBSEGFP. For DsRed mRNA, pDsRed1-N1 (Clontech) was digested with SalI and NotI, and then ligated to the SalI and NotI sites of pBlueScript $\mathrm{SK}^{-}$. The constructed plasmids were digested with NotI, and then mRNAs for EGFP, EGFP-actin, EGFP-IAP1 (sense and antisense), EGFP-MTA (sense and antisense), EGFPL1 (sense and antisense), and DsRed were synthesized using the mMessage mMachine $\mathrm{T} 7$ ultra kit (Ambion) according to the manufacturer's instructions. To synthesize EGFP-vector mRNA, pBS-EGFP was digested with AflIII.

FG oocytes from B6D2F1, mice were injected with 5-10 pL of either EGFP, EGFP-actin, EGFP-vector, EGFP-IAP1, EGFP- 
MTA, or EGFP-L1 mRNA solutions (50 nM) containing DsRed mRNA $(2.5 \mu \mathrm{M})$ as described (Nagy et al. 2003). The RNA-injected oocytes were cultured in CZB medium at $37^{\circ} \mathrm{C}$ under $5 \%$ $\mathrm{CO}_{2}$ in air. At 0,16 , and $40 \mathrm{~h}$ post-injection, five to 10 oocytes were collected, and then RNA was extracted and reverse transcribed using oligo(dT) primers. For quantitative analysis, EGFP and DsRed were amplified by ExTaq DNA polymerase (Takara) using the primers EGFPf plus EGFPr and DsRedf plus DsRedr (Supplementary Table S9), respectively. The relative band intensities were analyzed by computerized densitometry using Lane and Spot Analyzer (ATTO). These experiments were repeated five times. Relative EGFP values derived from EGFPretrotransposon mRNA injections were compared with those derived from cognate control injections by Dunnet's multiple comparison test.

Preparation of low-molecular-weight RNA and Northern blot analysis

To obtain the low-molecular-weight RNA fraction, total RNA solution was added with an equal amount of PEG solution (1.6 $\mathrm{M} \mathrm{NaCl}, 13 \%$ PEG 6000), and then the supernatant was precipitated using isopropanol. For Northern blot analysis of miRNAs and gsRNAs, $20 \mu \mathrm{g}$ of low-molecular-weight RNA was loaded on a $15 \%$ polyacrylamide gel and electroblotted onto a Hybond XL membrane (Amersham). Oligo DNA probes, which were complementary to miRNAs or gsRNAs, were labeled with T4 polynucleotide kinase in the presence of $\left[\gamma_{-}{ }^{32} \mathrm{P}\right]$ ATP. The membrane was prehybridized using PerfectHyb Plus (Sigma) for $1 \mathrm{~h}$ at $40^{\circ} \mathrm{C}$. Hybridization was performed for $20 \mathrm{~h}$ at $40^{\circ} \mathrm{C}$, and then membranes were washed four times using low-stringency washing buffer $(2 \times \mathrm{SSC}, 0.1 \% \mathrm{SDS})$ at $50^{\circ} \mathrm{C}$.

\section{Enzymatic analysis of gsRNAs}

Low-molecular-weight RNA $(\sim 1 \mathrm{mg})$ from adult testes was separated on a $15 \%$ polyacrylamide-urea gel, and then an $~ 30$-nt band mainly containing gsRNAs was excised. gsRNAs were extracted from the gel slice, and eventually $\sim 5 \mathrm{ng}$ of gsRNAs were collected. For nuclease analyses, $1 \mathrm{ng}$ of denatured gsRNAs were incubated with $1 \mathrm{U} / \mu \mathrm{L}$ DNaseI (Roche) or $10 \mu \mathrm{g} / \mathrm{mL}$ RNaseA (Nippon Gene) in $20 \mathrm{mM}$ Tris- $\mathrm{HCl}$ (pH 8.4), $2 \mathrm{mM} \mathrm{MgCl}$, and $50 \mathrm{mM} \mathrm{KCl}$ for $1 \mathrm{~h}$ at $37^{\circ} \mathrm{C}$. For terminal group analysis, $1 \mathrm{ng}$ of denatured gsRNAs were incubated with or without $20 \mathrm{U}$ of calf intestine alkaline phosphatase (Takara) for $1 \mathrm{~h}$ at $37^{\circ} \mathrm{C}$ and ligated using $10 \mathrm{U}$ of T4 RNA ligase (Takara) for $1 \mathrm{~h}$ at $15^{\circ} \mathrm{C}$.

\section{$R T-P C R$ of gsRNA precursors}

For expression analysis of gsRNA precursors, $1 \mu \mathrm{g}$ of total RNA from various tissues and the testes at various ages were reverse transcribed. gsRNA precursors (AC113269, AC125141, AC125187, AC130548, and AC153373), protein-coding genes $(\beta$-actin and Histone $\mathrm{H} 2 \mathrm{afx})$, and retrotransposons (IAP1 and LINE1) were amplified by KOD-plus-DNA polymerase (Toyobo) using the appropriate primers (Supplementary Table S9).

\section{Acknowledgments}

We thank Yukio Kurihara and Yuichiro Watanabe for comments on the manuscript; Yuko Hoki, Jisu Park, and Toru Suzuki for assistance with injection experiments; Hiroyasu Furuumi, Koji Tajino, and Yasumitu Nagao for supplying mice; and Akihiro Mori and Yoshiyuki Suzuki for discussion on sta- tistical analysis. We also thank the members of the Sasaki laboratory.

\section{References}

Ambros, V. 2004. The function of animal microRNAs. Nature 431: 350-355.

Ambros, V., Lee, R.C., Lavanway, A., Williams, P.T., and Jewell, D. 2003. MicroRNAs and other tiny endogenous RNAs in $C$. elegans. Curr. Biol. 13: 807-818.

Aravin, A. and Tuschl, T. 2005. Identification and characterization of small RNAs involved in RNA silencing. FEBS Lett. 579: 5830-5840.

Aravin, A.A., Lagos-Quintana, M., Yalcin, A., Zavolan, M., Marks, D., Snyder, B., Gaasterland, T., Meyer, J., and Tuschl, T. 2003. The small RNA profile during Drosophila melanogaster development. Dev. Cell 5: 337-350.

Bailey, T.L. and Elkan, C. 1994. Fitting a mixture model by expectation maximization to discover motifs in biopolymers. Proc. Int. Conf. Intell. Syst. Mol. Biol. 2: 28-36.

Bartel, D.P. 2004. MicroRNAs: Genomics, biogenesis, mechanism, and function. Cell 116: 281-297.

Bellve, A.R., Cavicchia, J.C., Millette, C.F., O’Brien, D.A., Bhatnagar, Y.M., and Dym, M. 1977. Spermatogenic cells of the prepuberal mouse. J. Cell Biol. 74: 68-85.

Borsani, O., Zhu, J., Verslues, P.E., Sunkar, R., and Zhu, J.K. 2005. Endogenous siRNAs derived from a pair of natural cis-antisense transcripts regulate salt tolerance in Arabidopsis. Cell 123: 1279-1291.

Carmell, M.A., Xuan, Z., Zhang, M.Q., and Hannon, G.J. 2002. The Argonaute family: Tentacles that reach into RNAi, developmental control, stem cell maintenance, and tumorigenesis. Genes \& Dev. 16: 2733-2742.

Chen, P.Y., Manninga, H., Slanchev, K., Chien, M., Russo, J.J., Ju, J., Sheridan, R., John, B., Marks, D.S., Gaidatzis, D., et al. 2005. The developmental miRNA profiles of zebrafish as determined by small RNA cloning. Genes \& Dev. 19: 12881293.

Deng, W. and Lin, H. 2002. miwi, a murine homolog of piwi, encodes a cytoplasmic protein essential for spermatogenesis. Dev. Cell 2: 819-830.

Du, T. and Zamore, P.D. 2005. microPrimer: The biogenesis and function of microRNA. Development 132: 4645-4652.

Duchaine, F.T., Wohlschlegel, A.J., Kennedy, S., Bei, Y., Conte Jr., D., Kaming, P., Brownell, D.R., Harding, S., Mitani, S., Ruvkun, G., et al. 2006. Functional proteomics reveals the biochemical niche of C. elegans DCR-1 in multiple smallRNA-mediated pathways. Cell 124: 343-354.

Elbashir, S.M., Harborth, J., Lendeckel, W., Yalcin, A., Weber, K., and Tuschl, T. 2001a. Duplexes of 21-nucleotide RNAs mediate RNA interference in cultured mammalian cells. $\mathrm{Na}$ ture 411: 494-498.

Elbashir, S.M., Lendeckel, W., and Tuschl, T. 2001b. RNA interference is mediated by 21 - and 22-nucleotide RNAs. Genes \& Dev. 15: 188-200.

Grishok, A., Sinskey, J.L., and Sharp, P.A. 2005. Transcriptional silencing of a transgene by RNAi in the soma of C. elegans. Genes \& Dev. 19: 683-696.

Handel, M.A. and Eppig, J.J. 1979. Sertoli cell differentiation in the testes of mice genetically deficient in germ cells. Biol. Reprod. 20: 1031-1038.

He, L. and Hannon, G.J. 2004. MicroRNAs: Small RNAs with a big role in gene regulation. Nat. Rev. Genet. 5: 522-531.

Herrera, L., Ottolenghi, C., Garcia-Oritz, J.E., Pellegrini, M., Manini, F., Ko, M.S., Nagaraja, R., Forabosco, A., and 
Schlessinger, D. 2005. Mouse ovary developmental RNA and protein markers from gene expression profiling. Dev. Biol. 279: 271-290.

Houbaviy, H.B., Murray, M.F., and Sharp, P.A. 2003. Embryonic stem cell-specific microRNAs. Dev. Cell 5: 351-358.

Hutvagner, G., McLachlan, J., Pasquinelli, A.E., Balint, E., Tuschl, T., and Zamore, P.D. 2001. A cellular function for the RNA-interference enzyme Dicer in the maturation of the let-7 small temporal RNA. Science 293: 834-838.

Kanellopoulou, C., Muljo, S.A., Kung, A.L., Ganesan, S., Drapkin, R., Jenuwein, T., Livingston, D.M., and Rajewsky, K. 2005. Dicer-deficient mouse embryonic stem cells are defective in differentiation and centromeric silencing. Genes \& Dev. 19: 489-501.

Khvorova, A., Reynolds, A., and Jayasena, S.D. 2003. Functional siRNAs and miRNAs exhibit strand bias. Cell 115: 209-216.

Kuramochi-Miyagawa, S., Kimura, T., Yomogida, K., Kuroiwa, A., Tadokoro, Y., Fujita, Y., Sato, M., Matsuda, Y., and Nakano, T. 2001. Two mouse piwi-related genes: miwi and mili. Mech. Dev. 108: 121-133.

Kuramochi-Miyagawa, S., Kimura, T., Ijiri, T.W., Isobe, T., Asada, N., Fujita, Y., Ikawa, M., Iwai, N., Okabe, M., Deng, W., et al. 2004. Mili, a mammalian member of piwi family gene, is essential for spermatogenesis. Development 131: 839-849.

Lagos-Quintana, M., Rauhut, R., Lendeckel, W., and Tuschl, T. 2001. Identification of novel genes coding for small expressed RNAs. Science 294: 853-858.

Lau, N.C., Lim, L.P., Weinstein, E.G., and Bartel, D.P. 2001. An abundant class of tiny RNAs with probable regulatory roles in Caenorhabditis elegans. Science 294: 858-862.

Lee, S.R. and Collins, K. 2006. Two classes of endogenous small RNAs in Tetrahymena thermophila. Genes \& Dev. 20: 2833.

Lim, L.P., Glasner, M.E., Yekta, S., Burge, C.B., and Bartel, D.P. 2003. Vertebrate microRNA genes. Science 299: 1540.

Lippman, Z. and Martienssen, R. 2004. The role of RNA interference in heterochromatic silencing. Nature 431: 364-370.

Liu, J., Carmell, M.A., Rivas, F.V., Marsden, C.G., Thomson, J.M., Song, J.J., Hammond, S.M., Joshua-Tor, L., and Hannon, G.J. 2004. Argonaute2 is the catalytic engine of mammalian RNAi. Science 305: 1437-1441.

Lu, J., Qian, J., Chen, F., Tang, X., Li, C., and Cardoso, W.V. 2005. Differential expression of components of the microRNA machinery during mouse organogenesis. Biochem. Biophys. Res. Commun. 334: 319-323.

Lyle, R., Watanabe, D., te Vruchte, D.T., Lerchner, W., Smrzka, O.W., Wutz, A., Schageman, J., Hahner, L., Davies, C., and Barlow, D.P. 2000. The imprinted antisense RNA at the Igf2R locus overlaps but does not imprint Mas1. Nat. Genet. 25: $19-21$.

Ma, J.B., Yuan, Y.R., Meister, G., Peli, Y., Tuschl, T., and Patel, D.J. 2005. Structural basis for 5 '-end-specific recognition of guide RNA by the A. fulgidus Piwi protein. Nature 434: 666-670.

Maestre, J., Tchenio, T., Dhellin, O., and Heidmann, T. 1995. mRNA retroposition in human cells: Processed pseudogene formation. $E M B O ~ J . ~ 14:$ 6333-6338.

Matranga, C., Tomari, Y., Shin, C., Bartel, D.P., and Zamore, P.D. 2005. Passenger-strand cleavage facilitates assembly of siRNA into Ago2-containing RNAi enzyme complexes. Cell 123: $607-620$.

Mochizuki, K., Fine, N.A., Fujisawa, T., and Gorovsky, M.A. 2002. Analysis of a piwi-related gene implicates small RNAs in genome rearrangement in Tetrahymena. Cell 110: 689699
Morris, K.V., Chan, S.W., Jacobsen, S.E., and Looney, D.J. 2004. Small interfering RNA-induced transcriptional gene silencing in human cells. Science 305: 1289-1292.

Murchison, E.P., Partridge, J.F., Tam, O.H., Cheloufi, S., and Hannon, G.J. 2005. Characterization of Dicer-deficient murine embryonic stem cells. Proc. Natl. Acad. Sci. 102: 1213512140.

Nagy, A., Gertsenstein, M., Vintersten, K., and Behringer, R. 2003. Manipulating the mouse embryo. Cold Spring Harbor Laboratory Press, Cold Spring Harbor, NY

Paillard, L., Omilli, F., Legagneux, V., Bassez, T., Maniey, D., and Osborne, H.B. 1998. EDEN and EDEN-BP, a cis element and an associated factor that mediate sequence-specific mRNA deadenylation in Xenopus embryos. EMBO J. 17: 278-287.

Park, C.W., Chen, Z., Kren, B.T., and Steer, C.J. 2004. Doublestranded siRNA targeted to the huntingtin gene does not induce DNA methylation. Biochem. Biophys. Res. Commun. 323: 275-280.

Peaston, A.E., Evsikov, A.V., Graber, J.H., de Vries, W.N., Holbrook, A.E., Solter, D., and Knowles, B.B. 2004. Retrotransposons regulate host genes in mouse oocytes and preimplantation embryos. Dev. Cell 7: 597-606.

Peragine, A., Yoshikawa, M., Wu, G., Albrecht, H.L., and Poethig, R.S. 2004. SGS3 and SGS2/SDE1/RDR6 are required for juvenile development and the production of trans-acting siRNAs in Arabidopsis. Genes \& Dev. 18: 2368-2379.

Pfeffer, S., Lagos-Quintana, M., and Tuschl, T. 2005. Cloning of small RNA molecules. In Current protocols in molecular biology (eds. R.B.F.M. Ausubel et al.), pp. 26.4.1-26.4.18. Wiley Interscience, New York.

Schwarz, D.S., Hutvagner, G., Du, T., Xu, Z., Aronin, N., and Zamore, P.D. 2003. Asymmetry in the assembly of the RNAi enzyme complex. Cell 115: 199-208.

Shi, H., Diikeng, A., Tschudi, C., and Ullu, E. 2004. Argonaute protein in the early divergent eukaryote Trypanosoma brucei: Control of small interfering RNA accumulation and retroposon transcript abundance. Mol. Cell. Biol. 24: 420-427.

Sijen, T. and Plasterk, R.H. 2003. Transposon silencing in the Caenorhabditis elegans germline by natural RNAi. Nature 426: 310-314.

Sleutels, F., Zwart, R., and Barlow, D.P. 2002. The non-coding Air RNA is required for silencing autosomal imprinted genes. Nature 415: 810-813.

Surdej, P. and Jacobs-Lorena, M. 1998. Developmental regulation of bicoid mRNA stability is mediated by the first 43 nucleotides of the 3' untranslated region. Mol. Cell. Biol. 18: 2892-2900.

Svoboda, P., Stein, P., Hayashi, H., and Schultz, R.M. 2000. Selective reduction of dormant maternal mRNAs in mouse oocytes by RNA interference. Development 127: 4147-4156.

Svoboda, P., Stein, P., Anger, M., Bernstein, E., Hannon, G.J., and Schultz, R.M. 2004a. RNAi and expression of retrotransposons MuERV-L and IAP in preimplantation mouse embryos. Dev. Biol. 269: 276-285.

Svoboda, P., Stein, P., Flipowicz, W., and Schultz, R.M. 2004b. Lack of homologous sequence-specific DNA methylation in response to stable dsRNA expression in mouse oocytes. Nucleic Acids Res. 32: 3601-3606.

Tomari, Y. and Zamore, P.D. 2005. Perspective: Machines for RNAi. Genes \& Dev. 19: 517-529.

van de Lagemaat, L.N., Landry, J.R., Mager, D.L., and Medstrand, P. 2003. Transposable elements in mammals promote regulatory variation and diversification of genes with specialized functions. Trends Genet. 19: 530-536.

Viveiros, M.M., O’Brien, M., and Eppig, J.J. 2004. Protein kinase 
C activity regulates the onset of anaphase I in mouse oocytes. Biol. Reprod. 71: 1525-1532.

Volpe, T.A., Kidner, C., Hall, I.M., Teng, G., Grewal, S.I., and Martienssen, R.A. 2002. Regulation of heterochromatic silencing and histone H3 lysine-9 methylation by RNAi. Science 297: 1833-1837.

Yan, W., Ma, L., Stein, P., Pangas, S.A., Burns, K.H., Bai, Y., Schultz, R.M., and Matzuk, M.M. 2005. Mice deficient in oocyte-specific oligoadenylate synthetase-like protein OAS1D display reduced fertility. Mol. Cell. Biol. 25: 46154624.

Yu, Z., Raabe, T., and Hecht, N.B. 2005. MicroRNA mirn122a reduces expression of the posttranscriptionally regulated germ cell transition protein2 (Tnp2) messenger RNA (mRNA) by mRNA cleavage. Biol. Reprod. 73: 427-433.

Yuan, Y.R., Pei, Y., Ma, J.B., Kuryavyi, V., Zhadina, M., Meister, G., Chen, H.Y., Dauter, Z., Tuschl, T., and Patel, D.J. 2005. Crystal structure of $A$. aeolicus Argonaute, a site-specific DNA-guided endoribonuclease, provides insights into RISCmediated mRNA cleavage. Mol. Cell 19: 405-419.

Zilberman, D., Cao, X., and Jacobsen, S.E. 2003. ARGONAUTE4 control of locus-specific siRNA accumulation and DNA and histone methylation. Science 299: 716-719.

Zuker, M. 2003. Mfold Web server for nucleic acid folding and hybridization prediction. Nucleic Acids Res. 31: 3406-3415. 


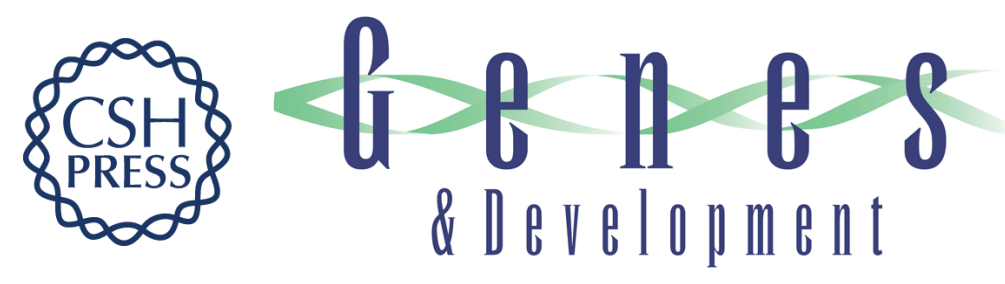

\section{Identification and characterization of two novel classes of small RNAs in the mouse germline: retrotransposon-derived siRNAs in oocytes and germline small RNAs in testes}

Toshiaki Watanabe, Atsushi Takeda, Tomoyuki Tsukiyama, et al.

Genes Dev. 2006, 20:

Access the most recent version at doi:10.1101/gad.1425706

Supplemental http://genesdev.cshlp.org/content/suppl/2006/06/09/gad.1425706.DC1
Material

Related Content A novel class of small RNAs in mouse spermatogenic cells

Shane T. Grivna, Ergin Beyret, Zhong Wang, et al.

Genes Dev. UNKNOWN , 2006 20: 1709-1714 Small RNAs just got bigger:

Piwi-interacting RNAs (piRNAs) in mammalian testes

V. Narry Kim

Genes Dev. UNKNOWN , 2006 20: 1993-1997 Perspective: machines for RNAi

Yukihide Tomari and Phillip D. Zamore

Genes Dev. March , 2005 19: 517-529

References This article cites 60 articles, 21 of which can be accessed free at:

http://genesdev.cshlp.org/content/20/13/1732.full.html\#ref-list-1

Articles cited in:

http://genesdev.cshlp.org/content/20/13/1732.full.html\#related-urls

License

Email Alerting Receive free email alerts when new articles cite this article - sign up in the box at the top Service right corner of the article or click here.

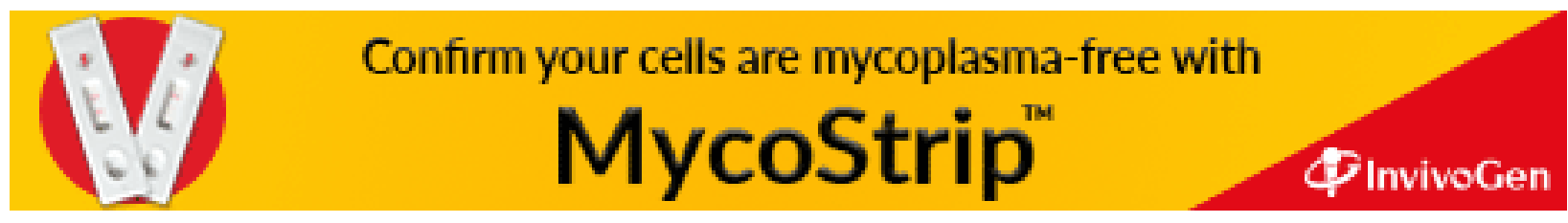

